ARTICLE

\title{
Upgrading ketone synthesis direct from carboxylic acids and organohalides
}

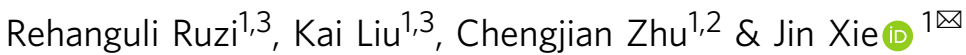

The ketone functional group has a unique reactivity in organic chemistry and is associated with a number of useful reactions. Catalytic methods for ketone synthesis are continually being developed. Here, we report a photoredox, nickel and phosphoranyl radical synergistic cross-electrophile coupling of commercially available chemicals, aromatic acids and aryl/alkyl bromides. This allows for concise synthesis of highly functionalized ketones directly, without the preparation of activated carbonyl intermediates or organometallic compounds, and thus complements the conventional Weinreb ketone synthesis. Use of the appropriate photocatalyst, ligand amount and solvents can match the reaction rate required by any simple catalytic cycle. The practicality and synthetic robustness of the reaction are illustrated by the facile synthesis of complex ketones from readily available feedstock chemicals.

\footnotetext{
${ }^{1}$ State Key Laboratory of Coordination Chemistry, Jiangsu Key Laboratory of Advanced Organic Materials, Chemistry and Biomedicine Innovation Center (ChemBIC), School of Chemistry and Chemical Engineering, Nanjing University, Nanjing 210023, China. ${ }^{2}$ College of Chemistry and Molecular Engineering, Zhengzhou University, Zhengzhou 450001, China. ${ }^{3}$ These authors contributed equally: Rehanguli Ruzi, Kai Liu. ${ }^{凶}$ email: xie@nju.edu.cn
} 
K etones play a prominent role in organic chemistry. The ketone moiety is extremely common in natural products and pharmaceuticals ${ }^{1}$ and in dyes, fragrancies and flavors $^{2}$. It is also a versatile reaction center in organic synthesis ${ }^{3}$. Many frequently used reactions, including the Mannich reaction, Wittig reaction, Grignard reaction, Passerini reaction, Baeyer-Villiger oxidation, and Wolff-Kishner-Huang reduction describe a wide array of transformations of ketones. The development of a practical route to ketones from feedstock chemicals has long been a subject of interest ${ }^{4-12}$. Carboxylic acids and organohalides are commercially abundant and structurally diverse, bench-stable feedstock chemicals commonly used in organic synthesis (Fig. 1a). When producing ketones from carboxylic acids and organohalides, the stoichiometric approach requires preparation of necessary intermediates such as amides or aldehydes and Grignard reagents ${ }^{13,14}$. If aldehydes are employed, reoxidation is necessary ${ }^{15}$. Catalytic strategies for production of ketones rely on transition metal-catalyzed carbon-carbon coupling between activated carbonyls such as acid chlorides or anhydrides with organometallic reagents (Fig. 1b) ${ }^{16-19}$. However, activated carbonyls are generally prepared in as many as three steps from carboxylic acids and organometallics are obtained typically by metalation of organohalides ${ }^{20}$, which can often lead to poor functional group compatibility or a lengthy functional group protection/deprotection process.

In recent years, nickel-catalyzed cross-electrophile coupling has attracted considerable attention ${ }^{21-30}$. The carbon-carbon coupling arises from two different electrophiles in the presence of stoichiometric reductant. We posited that a carboxylic acid could be directly used as a latent electrophile (Cterminus) rather than a nucleophile (O-terminus) in crosscoupling. This could simplify and upgrade ketone synthesis from carboxylic acids and organic halides ${ }^{13}$. Very recently, our group and Doyle et al. reported an elegant photoredoxpromoted mild deoxygenation of carboxylic acids generating acyl radicals ${ }^{31-35}$. Since photoredox and nickel-catalyzed C-O bond formation between carboxylic acids and aromatic bromides has been reported ${ }^{36}$ to achieve the desired crosselectrophile coupling, acyl radical oxidative addition by a metallaphotoredox pathway ${ }^{37-41}$ is essential to suppress the $\mathrm{C}-\mathrm{O}$ bond formation (Fig. 1c). Alternatively, a judicious strategy reported by Gong et al. is conversion of carboxylic acid into anhydrides in situ to suppress the C-O coupling ${ }^{22,23}$. However, the use of free carboxylic acids as acyl radical precursors is a challenge in the oxidative addition step as a result of the strong bond dissociation energy of the $\mathrm{C}-\mathrm{O}$ bond $\left(106 \mathrm{kcal} \mathrm{mol}^{-1}\right)^{33}$.

A proposed mechanism for the designed metallaphotoredox cross-electrophile coupling is shown in Fig. 2. The photoexcited $*\left[\operatorname{Ir}\left(\mathrm{dF}\left(\mathrm{CF}_{3}\right) \text { ppy }\right)_{2}(\mathrm{dtbbpy})\right] \mathrm{PF}_{6}\left[{ }^{1 / 2} E_{\text {red }}\left({ }^{*} \mathrm{Ir}{ }^{\mathrm{III}} / \mathrm{Ir}^{\mathrm{II}}\right)=\right.$ $+1.21 \mathrm{~V}$ vs SCE, $\tau=2.3 \mu \mathrm{s}]^{38}$ causes single-electron transfer

a

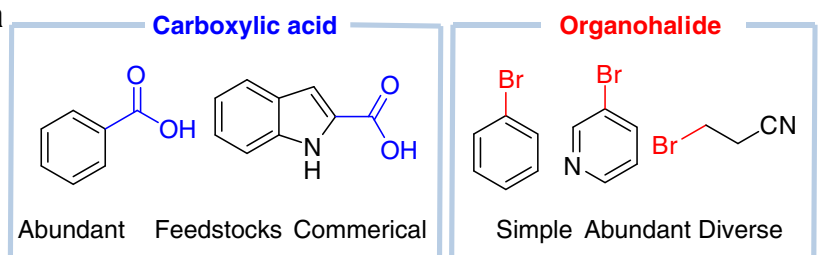

b
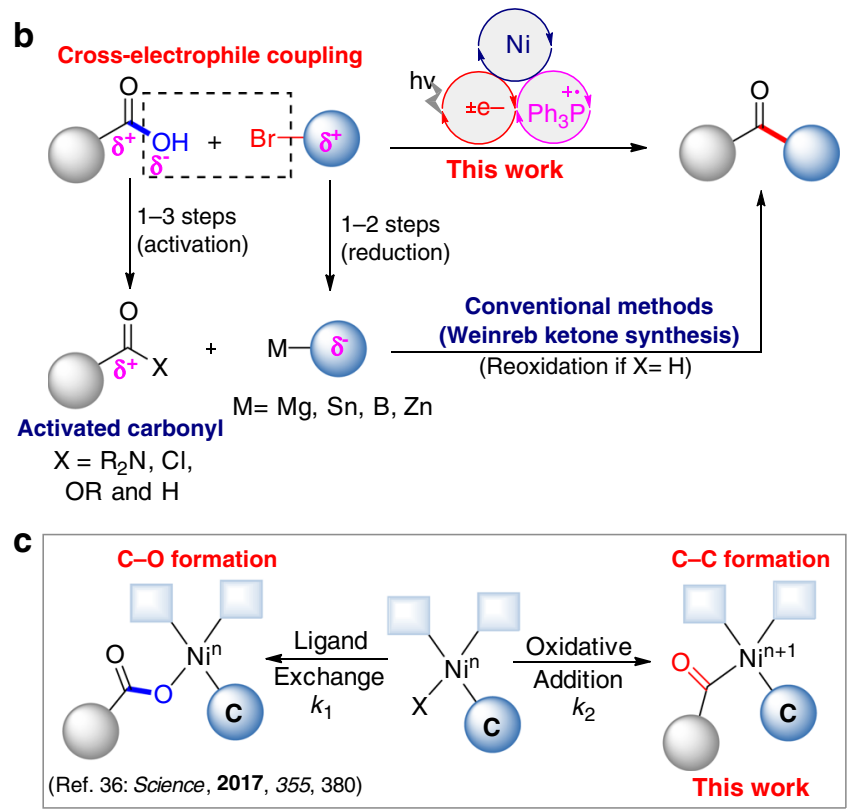

Fig. 1 Catalytic cross-electrophile coupling between carboxylic acids and organohalides. a The abundant feedstock chemicals in synthetic lab. b Direct cross-electrophile coupling of acid and organohalides. c Key challenge: $\mathrm{C}-\mathrm{O}$ versus $\mathrm{C}-\mathrm{C}$ formation.

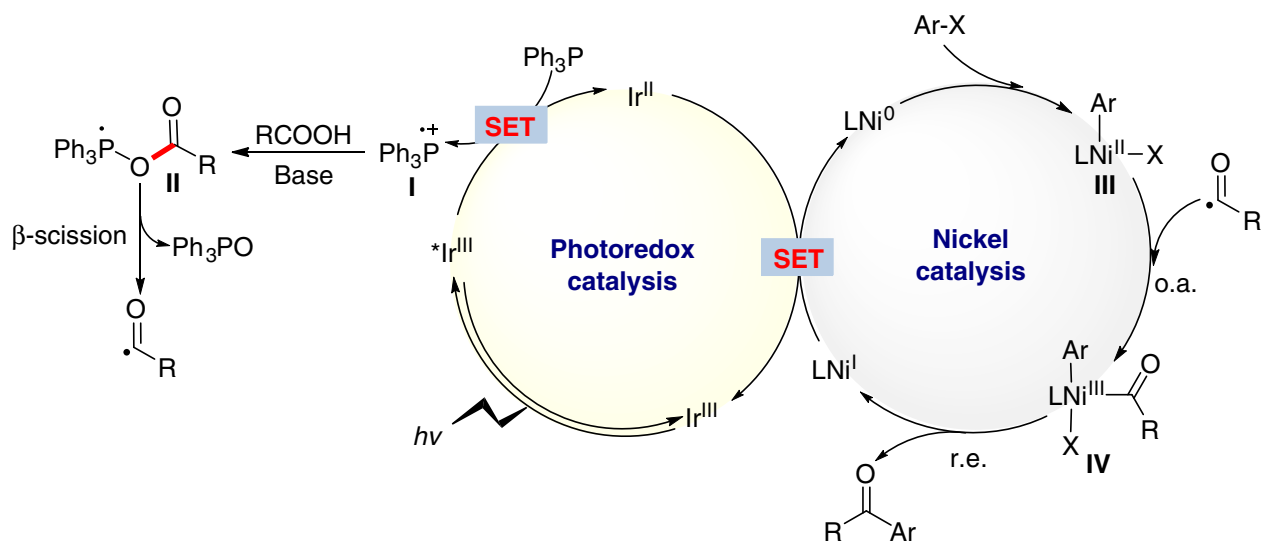

Fig. 2 Proposed mechanism. Mechanistic proposal for cross-electrophile coupling of acid and aryl bromides. o.a. oxidative addition, r.e. reductive elimination. 
Table 1 Optimization of the reaction conditions.

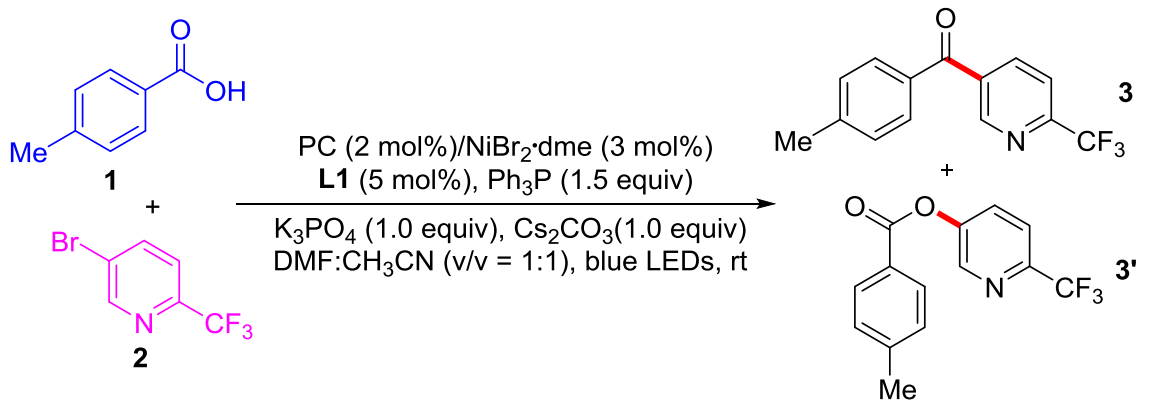

\begin{tabular}{lll} 
Entry & Variation of standard conditions & Isolated yield: \\
\hline 1 & None & $82 \%(16 \%)$ \\
2 & $10 \mathrm{~mol} \% \mathbf{L 1}$ & $46 \%(37 \%)$ \\
3 & $15 \mathrm{~mol} \% \mathbf{L 1}$ & $23 \%(53 \%)$ \\
4 & $3 \mathrm{~mol} \%$ of $\mathbf{~ L 1}$ & $19 \%(10 \%)$ \\
5 & $5 \mathrm{~mol} \% \mathbf{L 2}$ & $31 \%(33 \%)$ \\
6 & $5 \mathrm{~mol} \% \mathbf{L 3}$ & $42 \%(28 \%)$ \\
7 & $5 \mathrm{~mol} \% \mathbf{L 4}$ & $35 \%(40 \%)$ \\
8 & $5 \mathrm{~mol} \% \mathbf{L 5}$ & nd \\
9 & $5 \mathrm{~mol} \% \mathbf{L 6}$ & nd \\
10 & $\mathrm{DCM}$ instead of $\mathrm{DMF} / \mathrm{MeCN}$ & nd \\
11 & $\mathrm{DMA}$ instead of $\mathrm{DMF} / \mathrm{MeCN}$ & $25 \%(17 \%)$ \\
12 & no PC or $\mathrm{NiBr}_{2}$ or $\mathrm{Ph}{ }_{3} \mathrm{P}$ or light & nd
\end{tabular}

Standard conditions: photocatalyst ( $2 \mathrm{~mol} \%), \mathrm{NiBr}_{2} \cdot \mathrm{dme}(3 \mathrm{~mol} \%), \mathbf{L 1}(5 \mathrm{~mol} \%), \mathbf{1 a}(0.2 \mathrm{mmol}), \mathbf{2 a}(0.4 \mathrm{mmol}), \mathrm{Ph}_{3} \mathrm{P}(0.3 \mathrm{mmol}), \mathrm{K}_{3} \mathrm{PO}_{4}(0.2 \mathrm{mmol}), \mathrm{Cs}_{2} \mathrm{CO}_{3}(0.2 \mathrm{mmol}), \mathrm{DMF}-\mathrm{CH}_{3} \mathrm{CN}(2.0 \mathrm{~mL}, \mathrm{v} / \mathrm{v}=$ 1:1), blue LEDs, ambient temperature, $20 \mathrm{~h}$.

DMF N,N-dimethylformamide; DMA N,N-dimethylacetamide, DCM dichloromethane, DME 1,2-dimethoxyethane, nd not detected

(SET) oxidation of triphenylphosphine $\left(E_{\text {red }}=+0.98 \mathrm{~V}\right.$ vs SCE $)^{31}$, as indicated by our Stern-Volmer experimental results (see Supplementary Fig. 7). The triphenylphosphine radical cation (I) generated recombines with the carboxylate anion to form a phosphoranyl radical intermediate (II). Owing to the strong affinity between the phosphoranyl radical and oxygen, a facile $\beta$-scission of the radical species (II) occurs, giving rise to a nucleophilic acyl radical ${ }^{42}$, which can undergo oxidative addition to the resulting aryl- $\mathrm{Ni}^{\mathrm{II}}$ species (III) giving the $\mathrm{Ni}^{\mathrm{III}}$ species (IV $)^{43-45}$. Finally, reductive elimination from the $\mathrm{Ni}^{\mathrm{III}}$ intermediate (IV) can generate the desired cross-electrophile coupling product, R-CO-Ar. A second SET event from $\mathrm{Ir}^{\mathrm{II}}$ $\left(\left[\mathrm{Ir}^{\mathrm{III}} / \mathrm{Ir}^{\mathrm{II}}\right]=-1.37 \mathrm{~V}\right.$ vs $\left.\mathrm{SCE}\right)$, leading to an $\mathrm{Ni}^{\mathrm{I}}$ species completes both catalytic cycles. The synergistic combination of photoredox with nickel catalysis proposed in Fig. 2 is a subject of continuing research ${ }^{46-58}$, and several challenges remain in this cross-electrophile coupling and must be addressed: (1) Efficient control of the matching of the $\mathrm{C}-\mathrm{O}$ bond cleavage and the radical addition to the nickel center; (2) weakening of the interference of stoichiometric triphenylphosphine in the nickel catalytic unit; and (3) use of appropriate ligands and solvents to significantly suppress the $\mathrm{C}-\mathrm{O}$ bond formation. Herein, we report a formal cross-electrophile coupling of carboxylic acids with aryl or alkyl halides enabled by photoredox and nickel catalysis, and phosphoranyl radical synergistic chemistry, leading to concise synthesis of ketones (Fig. 1b).

\section{Results}

Reaction optimization. Our investigation of this crosselectrophile coupling began with the reaction of 4-methylbenzoic acid (1) with 5-bromo-2-(trifluoromethyl) pyridine (2), and the representative results are presented in Table 1.

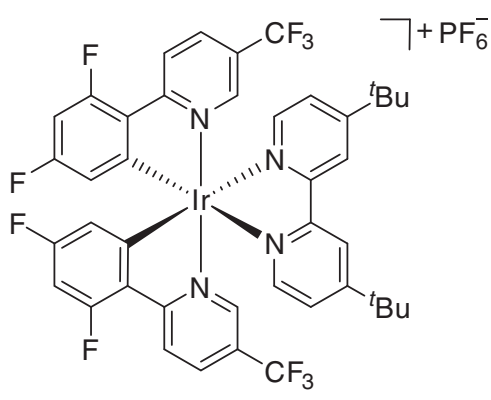

Photocatalyst (PC)<smiles>COc1ccnc(-c2cc(OC)ccn2)c1</smiles><smiles>Cc1ccnc(-c2cc(C)ccn2)c1</smiles>

L3<smiles>c1ccc(-c2ccccn2)nc1</smiles>

L4<smiles>FC(F)(F)c1ccnc(-c2cc(C(F)(F)F)ccn2)c1</smiles>

L5<smiles>c1cc(C2=NCCO2)nc(C2=NCCO2)c1</smiles>

L6
Fig. 3 Photocatalysts and ligands. Catalysts and ligands for crosselectrophile coupling of acid and aryl bromides.

The optimized reaction conditions include $2 \mathrm{~mol} \%\left[\operatorname{Ir}\left\{\mathrm{dF}\left(\mathrm{CF}_{3}\right)\right.\right.$ ppy $\}_{2}\{$ dtbbpy\} $] \mathrm{PF}_{6}, 3 \mathrm{~mol} \% \mathrm{NiBr}_{2}$.dme together with $5 \mathrm{~mol} \%$ $4,4^{\prime}$-di-tert-butyl-2,2'-bipyridine (L1, Fig. 3) and 1.5 equiv $\mathrm{Ph}_{3} \mathrm{P}$ with a mixed DMF- $\mathrm{CH}_{3} \mathrm{CN}$ solvent (entry 1 , Table 1 ). Under the standard conditions, the desired cross-electrophile coupling product (3) can be obtained in $82 \%$ yield while the yield of the $\mathrm{C}-\mathrm{O}$ coupling process, giving $3^{\prime}$ is suppressed to $16 \%$. We found the loading amount of ligand plays an important role in 
the control of the $\mathrm{C}-\mathrm{C}$ and $\mathrm{C}-\mathrm{O}$ bond formation (entries 2-4, Table 1). An increased or decreased loading amount of $4,4^{\prime}$-ditert-butyl-2,2'-bipyridine can facilitate the formation of the $\mathrm{C}-\mathrm{O}$ coupling by-product $\left(3^{\prime}\right)$. Screening of different ligands and solvents indicated that both a ligand effect and a solvent effect are crucial for a successful cross-electrophile coupling (entries 5-11, Table 1). We speculated that only compatible consecutive steps with well-matched rates would benefit this cross-electrophile coupling. In the absence of either photocatalyst, $\mathrm{NiBr}_{2} \cdot \mathrm{dme}$, triphenylphosphine or light irradiation, the model reaction failed to occur. The quantum yield of the model reaction was determined to be 0.35 , arguing against a radical chain pathway.

Substrate scope. With the optimized conditions in hand, we investigated the scope of the cross-electrophile coupling reaction with regard to aromatic carboxylic acids, and obtained the results in Fig. 4. In general, this protocol is highly efficient and has a broad substrate scope. The electron-rich and electronpoor functional groups on the ortho-, meta-, and para-positions on the phenyl groups of the aromatic acids have little influence on the coupling process and the desired ketones (3-21) are formed in $62-83 \%$ yield. A series of useful functional groups, such as bromine (6), reactive carbonyl groups (13-16), a terminal alkene (18), an internal alkyne (19) and an acetal (21) tolerate the reaction conditions well. Some of these functional groups have difficulty surviving the conventional Weinreb ketone synthesis method toward Grignard reagents. Heteroaromatic carboxylic acids are satisfactory starting materials and can uniformly produce the synthetically valuable diheteroaromatic ketones (22-26) with moderate to good yields. However, examination of the reaction of aliphatic carboxylic acids under these standard conditions showed that only a trace amount of the desired product can be produced while both decarboxylative $\mathrm{C}-\mathrm{C}$ coupling and direct $\mathrm{C}-\mathrm{O}$ coupling can occur.

Subsequently, we studied the substrate scope of aromatic bromides (Fig. 5) and found that many commercially available aromatic bromides can be used to deliver the desired ketones (27-46) in good yields. The excellent functional group tolerance of -COOR $(28,33,44,45),-C N(29,34)$, terminal unsaturated chemical bonds $(43,44)$, and heteroarenes $(38-43$, 46) support the practicality of the reaction. With this strategy, it is also very easy to construct fluorine- and fluoroalkylcontaining diaryl ketones $(30-32,36,37,39-42)$ with acceptable yields. Several alkyl halides also serve as coupling partners in this cross-electrophile coupling reaction, leading to functionalized ketones (47-49) in good yields (up to 92\%). When benzyl chloride was employed, $46 \%$ yield of ketone (49) was obtained and a significant amount of by-product ester was formed possibly because of the nucleophilic substitution side reaction. This coupling reaction can allow for the construction of highly functionalized ketones in an operationally simple, step-economical and gram-scale reaction (29, $5 \mathrm{mmol}$ scale).

Synthetic application. To further demonstrate the synthetic robustness of the reaction, we applied the strategy for the construction of a series of complex ketones from carboxylic acids and aromatic bromides (Fig. 6). Fenofibrate (50) is a drug used to adjust lipid levels and blood viscosity and it could be prepared in one step in $65 \%$ yield. The complex ketones (50-55) can be obtained in synthetically useful yields. The precise crosselectrophile coupling also allows for introduction of functional groups at an early synthetic stage to limit the number of synthetic steps thus improving the efficiency.

Mechanism of stoichiometric reactions. We performed the stoichiometric reactions of $\mathrm{Ar}-\mathrm{Ni}$ (II) intermediate (56) with 1.5 equiv. $\mathrm{Ph}_{3} \mathrm{P}$ in $\mathrm{DMF} / \mathrm{MeCN}$. Interestingly, no ligand exchange was observed by ${ }^{31} \mathrm{P}$ NMR analysis (Fig. 7, also see Supplementary Fig. 10). Treatment of $\mathrm{Ar}-\mathrm{Ni}(\mathrm{II})$ intermediate (56) under the photoredox conditions, led to the desired deoxygenative $\mathrm{C}-\mathrm{C}$ coupling product (35), which was obtained in $42 \%$ yield, further supporting the proposed mechanism (Fig. 7).

\section{Discussion}

We have developed a cross-electrophile coupling between aromatic carboxylic acids and organic bromides, inexpensive and abundant feedstock chemicals, enabled by photoredox and a nickel and phosphoranyl radical synergistic combination, affording a wide array of structurally diverse ketones with excellent functional group compatibility. This strategy for ketone synthesis can significantly improve the synthetic efficiency and step-economy, and it also opens a door to construct highly functionalized or complex ketones which are still difficult to prepare by a conventional Weinreb ketone synthesis. We found that the use of appropriate ligand loading amount ( $5 \mathrm{~mol} \%$ of $4,4^{\prime}$-di-tert-butyl-2,2'-bipyridine), mixed solvents $\left(\mathrm{DMF} / \mathrm{CH}_{3} \mathrm{CN}\right)$ and combined inorganic bases $\left(\mathrm{K}_{3} \mathrm{PO}_{4}\right.$ and $\mathrm{Cs}_{2} \mathrm{CO}_{3}$ ) is crucial to achieve the desired $\mathrm{C}-\mathrm{C}$ bond formation reactions, affording the desired ketone products. The employment of more or less of ligand results in a sharply decreased yield of the ketone product and an increased yield of the ester by-product. Use of combined bases and mixed solvents would improve the deprotonation of carboxylic acids to expedite the acyl radical generation and use of the precise amount of a ligand would promote the acyl radical oxidative addition to the arylnickel (II) species. We speculated that a facile $\mathrm{C}-\mathrm{O}$ bond cleavage and subsequent rapid acyl radical oxidative addition rate can control the selective $\mathrm{C}-\mathrm{C}$ bond formation. We believe this cross-electrophile coupling strategy of carboxylic acids and organic halides will upgrade the synthesis of ketones with great potential application in organic synthesis, drug discovery and optochemical biology given the importance and ubiquity of ketones.
Methods
General procedure for cross-electrophile coupling of carboxylic acids and organohalides. Preparation of Ni-based catalyst solution: In the nitrogen-filled glove box, a stirring bar, $\mathrm{NiBr}_{2}$.dme $(1.9 \mathrm{mg}, 3.0 \mathrm{~mol} \%)$, 4,4'-di-tert-butyl-2,2'- bipyridine $(2.7 \mathrm{mg}, 5.0 \mathrm{~mol} \%)$ and $\mathrm{CH}_{3} \mathrm{CN} / \mathrm{DMF}(2.0 \mathrm{~mL}, V / V=1: 1)$ were suc- cessively added to an oven-dried vial $(8 \mathrm{~mL}$ screw-cap threaded). The vial was then sealed with a Teflon-lined plastic screw-cap and stirred until the resulting mixture become homogeneous (about $20 \mathrm{~min}$ ).
Photocatalyst $\operatorname{Ir}\left[\mathrm{dF}\left(\mathrm{CF}_{3}\right) \mathrm{ppy}\right]_{2}(\mathrm{dtbbpy}) \mathrm{PF}_{6}(4.5 \mathrm{mg}, 2 \mathrm{~mol} \%)$, aromatic carboxylic acid ( $0.2 \mathrm{mmol}, 1.0$ equiv), aryl bromide ( $0.4 \mathrm{mmol}, 2.0$ equiv), $\mathrm{Ph}_{3} \mathrm{P}$ (78.6 mg, $0.3 \mathrm{mmol}, 1.5$ equiv), anhydrous powder $\mathrm{K}_{3} \mathrm{PO}_{4}(42.4 \mathrm{mg}, 0.2 \mathrm{mmol}$, 1.0 equiv), and anhydrous powder $\mathrm{Cs}_{2} \mathrm{CO}_{3}(65.0 \mathrm{mg}, 0.2 \mathrm{mmol}, 1.0$ equiv) were added to an oven-dried $10 \mathrm{~mL}$ Schlenk tube equipped with a magnetic stirring bar. The tube was evacuated and backfilled with argon three times. Subsequently, the nickel-catalyst solution was transferred into this Schlenk tube under argon. The tube was then sealed and placed $\sim 5 \mathrm{~cm}$ from $2 \times 45 \mathrm{~W}$ blue LEDs. The reaction mixture was stirred for $20-36 \mathrm{~h}$ at room temperature (air-condition was used to keep the temperature is $25^{\circ} \mathrm{C}$ or so). After completion, the reaction mixture was removed from the light, diluted with water and the aqueous layer was extracted with EtOAc $(3 \times 2.0 \mathrm{~mL})$. The combined organic layers were washed with brine, dried over anhydrous $\mathrm{Na}_{2} \mathrm{SO}_{4}$, filtered, and concentrated. The residue was purified by flash chromatography on silica gel to afford the corresponding ketone products. 


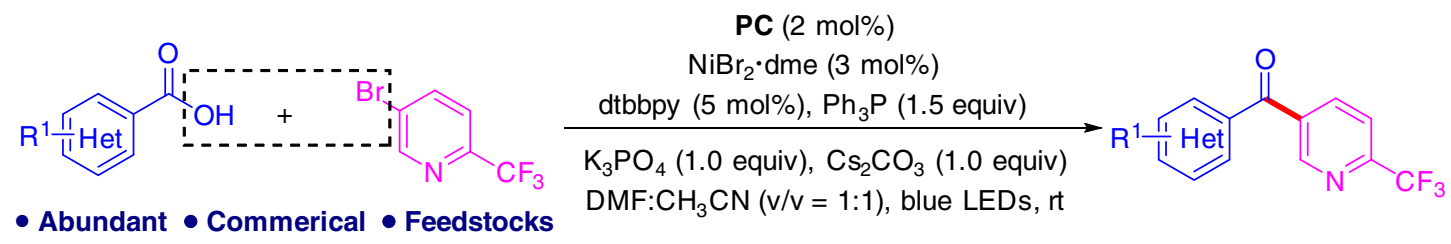

- Abundant • Commerical • Feedstocks DMF: $\mathrm{CH}_{3} \mathrm{CN}(\mathrm{v} / \mathrm{v}=1: 1)$, blue LEDs, it<smiles>Cc1ccc(C(=O)c2ccc(C(F)(F)F)nc2)cc1</smiles><smiles>O=C(c1ccc(Br)cc1)c1ccc(C(F)(F)F)nc1</smiles>

6: $66 \%(91: 9)$<smiles>Cc1ccc(Cl)cc1C(=O)c1ccc(C(F)(F)F)nc1</smiles><smiles>Cc1cccc(C(=O)c2ccc(C(F)(F)F)nc2)c1</smiles>

$12: 77 \%(88: 12)$<smiles>O=Cc1cccc(C(=O)c2ccc(C(F)(F)F)nc2)c1</smiles>

15: $66 \%(91: 9)$<smiles>C=CCOc1cccc(C(=O)c2ccc(C(F)(F)F)nc2)c1</smiles>

18: $77 \%(95: 5)$<smiles>O=C(c1ccc(C(F)(F)F)nc1)c1ccc2c(c1)OCO2</smiles>

21: $81 \%(94: 6)$

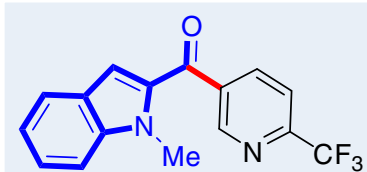

24: $71 \%(95: 5)$<smiles>O=C(c1ccc(F)cc1)c1ccc(C(F)(F)F)nc1</smiles>

4: $70 \%(86: 14)$<smiles>Cc1ccc(C(=O)c2ccc(C(F)(F)F)nc2)cc1F</smiles><smiles>COc1cc(Cl)cc(C(=O)c2ccc(C(F)(F)F)nc2)c1</smiles>

10: $62 \%(96: 4)$<smiles>O=C(c1ccccc1)c1cccc(C(=O)c2ccc(C(F)(F)F)nc2)c1</smiles>

13: $70 \%(91: 9)^{\mathrm{a}}$<smiles>O=C(Nc1ccc(C(=O)c2ccc(C(F)(F)F)nc2)cc1)c1ccccc1</smiles>

16: $82 \%(91: 9)^{a}$<smiles>O=C(c1ccc(C(F)(F)F)nc1)c1cccc(C#Cc2ccccc2)c1</smiles>

19: $65 \%(88: 12)^{\mathrm{a}}$<smiles>O=C(c1ccc(C(F)(F)F)nc1)c1ccsc1</smiles>

22: $82 \%(95: 5)$<smiles>Cn1cccc1C(=O)c1ccc(C(F)(F)F)nc1</smiles>

25: $68 \%(96: 4)$<smiles>O=C(c1ccc(Cl)cc1)c1ccc(C(F)(F)F)nc1</smiles>

5: $76 \%(>99: 1)$<smiles>Cc1ccc(C(=O)c2ccc(C(F)(F)F)nc2)cc1C(F)(F)F</smiles>

8: $67 \%(85: 15)$<smiles>O=C(c1ccc(C(F)(F)F)nc1)c1ccc2ccccc2c1</smiles>

11: $77 \%(>99: 1)$<smiles>COC(OC)c1cccc(C(=O)c2ccc(C(F)(F)F)nc2)c1</smiles>

14: $76 \%(95: 5)$<smiles>O=C(c1ccc(C(F)(F)F)nc1)c1ccccc1OC(F)(F)F</smiles>

17: $62 \%(95: 5)$<smiles>O=C(c1ccc(C(F)(F)F)nc1)c1ccc2occc2c1</smiles>

20: $81 \%(98: 2)$<smiles>O=C(c1ccc(C(F)(F)F)nc1)c1csc2ccccc12</smiles>

23: $86 \%(98: 2)$<smiles>O=C(c1ccc(C(F)(F)F)nc1)c1ccoc1</smiles>

26: $57 \%(>99: 1)$

Fig. 4 Carboxylic acid scope at a $\mathbf{0 . 2} \mathbf{~} \mathbf{~ m o l}$ scale under standard conditions. The isolated yield of ketone is given for product and the GC ratio of ketone

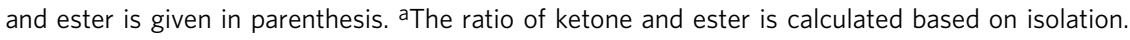




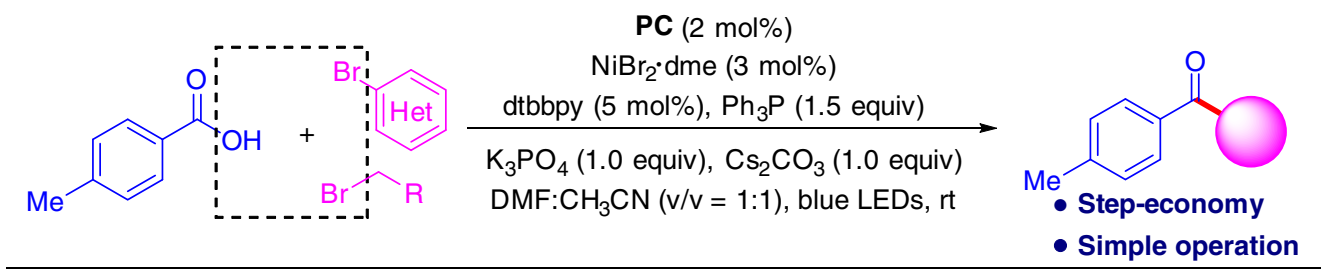<smiles>COc1ccc(C(=O)c2ccc(C)cc2)cc1</smiles>

27: $68 \%(96: 4)$<smiles>Cc1ccc(C(=O)c2ccc(C(F)(F)F)cc2)cc1</smiles>

30: $81 \%(96: 4)$<smiles>CC(=O)c1cccc(C(=O)c2ccc(C)cc2)c1</smiles>

33: $81 \%(91: 9)$<smiles>Cc1ccc(C(=O)c2cc(C(F)(F)F)cc(C(F)(F)F)c2)cc1</smiles>

37: $66 \%(94: 6)$<smiles>Cc1ccc(C(=O)c2cncc(C(F)(F)F)c2)cc1</smiles>

40: $70 \%(95: 5)$<smiles>Cc1ccc(C(=O)c2cnc3ccccc3c2)cc1</smiles>

43: $50 \%(94: 6)$<smiles>CCOC(=O)c1ccc(C(=O)c2ccc(C)cc2)cc1</smiles>

28: $84 \%(96: 4)$<smiles>Cc1ccc(C(=O)c2ccc(C(F)(F)F)cc2)cc1</smiles>

31: $80 \%(90: 10)$<smiles>Cc1ccc(C(=O)c2ccc(C#N)cc2)cc1</smiles>

29: $87 \%(98: 2)$ 5 mmol: $82 \%$<smiles>Cc1ccc(C(=O)c2cccc(OC(F)(F)F)c2)cc1</smiles>

32: $48 \%(90: 10)$<smiles>[R]c1ccccc1C(=O)c1ccc(C)cc1</smiles>

34: $\mathrm{R}=\mathrm{CN}, 79 \%(88: 12)$ 35: $R=M e, 61 \%(87: 13)$<smiles>Cc1ccc(C(=O)c2cccs2)cc1</smiles>

38: $71 \%(95: 5)$<smiles>Cc1ccc(C(=O)c2ccc(F)nc2)cc1</smiles>

41: $62 \%(98: 2)$<smiles>Cc1ccc(C(=O)c2ccc(F)c(C(F)(F)F)c2)cc1</smiles>

36: $77 \%(96: 4)$<smiles>CC(=O)c1ccc(C(=O)c2ccc(C)cc2)o1</smiles>

39: $57 \%(95: 5)$<smiles>C#CCCCCOC(=O)c1ccc(C(=O)c2ccc(C)cc2)cc1</smiles>

45: $61 \%(87: 13)^{\mathrm{a}}$<smiles>C=CCCCCOC(=O)c1ccc(C(=O)c2ccc(C)cc2)cc1</smiles>

44:79\% $(92: 8)^{\mathrm{a}}$<smiles>Cc1ccc(C(=O)c2cnc(C(F)(F)F)nc2)cc1</smiles>

42: $81 \%(93: 7)$<smiles>Cc1ccc(C(=O)c2cnn(C(=O)OC(C)(C)C)c2)cc1</smiles>

46: $38 \%(88: 12)^{a}$<smiles>Cc1ccc(C(=O)CCC#N)cc1</smiles><smiles>CC(=O)CCC(=O)c1ccc(C)cc1</smiles>

48: $68 \%(96: 4)$<smiles>CCCCCC(C)(C)OC(=O)c1ccc(C)cc1</smiles>

Fig. $\mathbf{5}$ Organohalide scope on a $\mathbf{0 . 2} \mathbf{~} \mathbf{m m o l}$ scale under standard conditions. The isolated yield of ketone is given and the GC ratio of ketone and ester is

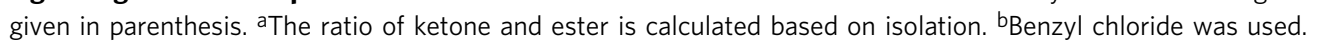


<smiles>COc1ccc(-c2ccc3cc(C(=O)c4ccc(C(F)(F)F)nc4)ccc3c2)cc1C12CC3CC(C1)C(C2)C3[B]OC(C)(C)C(C)(C)C</smiles><smiles>Cc1ccc(C(=O)c2ccc(C(=O)OC[C@H]3O[C@@H]4OC(C)(C)O[C@@H]4[C@H]4OC(C)(C)O[C@@H]43)cc2)cc1</smiles><smiles>Cc1ccc(C(=O)c2ccc(C(=O)O[C@@H]3O[C@@H]4OC(C)(C)OC4O[C@H]3[C@H]3COC(C)(C)O3)cc2)cc1</smiles><smiles>CC(C)=CCC/C(C)=C/COC(=O)c1ccc(C(=O)c2ccc(C)cc2)cc1</smiles>

Fig. 6 Concise synthesis of complex ketones. Carboxylic acids are blue and aromatic bromides are pink. The isolated yield of by-product ester is given in parenthesis.

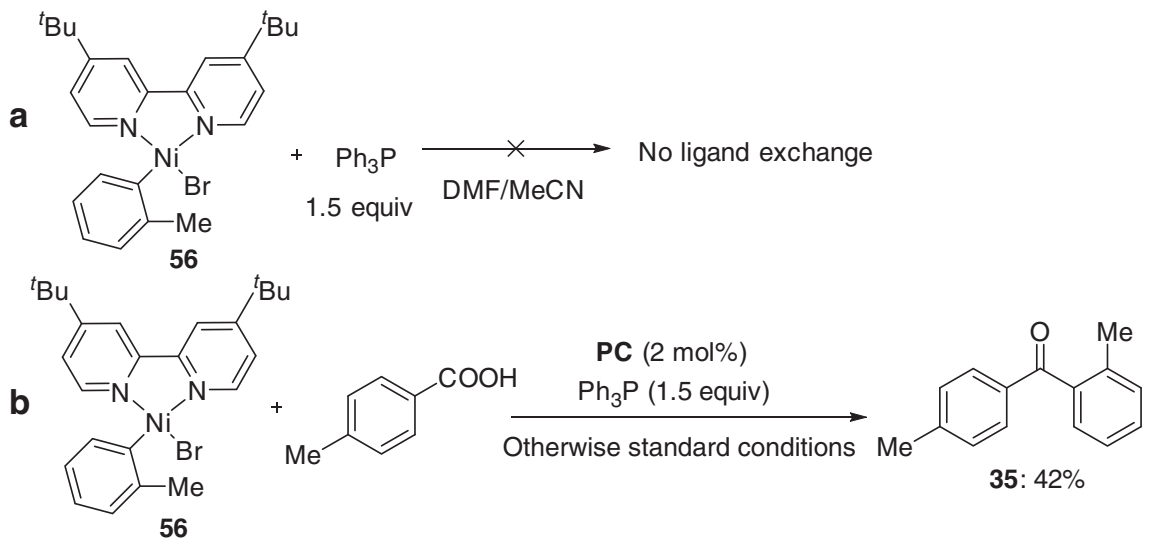

Fig. 7 Mechanistic studies. a The reaction of $\mathrm{Ph}_{3} \mathrm{P}$ with $\mathrm{Ar}-\mathrm{Ni}(\mathrm{II})$ intermediates. b Stoichiometric reactions of $\mathrm{Ar}-\mathrm{Ni}(\mathrm{II})$ intermediates.

\section{Data availability}

The authors declare that all other data supporting the findings of this study are available within the article and Supplementary Information files, and also are available from the corresponding author upon reasonable request.

Received: 11 March 2020; Accepted: 15 June 2020;

Published online: 03 July 2020

\section{References}

1. McDaniel, R. et al. Multiple genetic modifications of the erythromycin polyketide synthase to produce a library of novel "unnatural" natural products. Proc. Natl Acad. Sci. USA 96, 1846-1851 (1999).
2. Tan, Y. \& Siebert, K. J. Quantitative structure-activity relationship modeling of alcohol, ester, aldehyde, and ketone flavor thresholds in beer from molecular features. J. Agric. Food Chem. 52, 3057-3064 (2004).

3. Otera, J. (ed.) Modern Carbonyl Chemistry (Wiley-VCH, 2000).

4. Brunet, J. J. \& Chauvin, R. Synthesis of diarylketones through carbonylative coupling. Chem. Soc. Rev. 24, 89-95 (1995).

5. Li, Y., Hu, Y. \& Wu, X. F. Non-noble metal-catalysed carbonylative transformations. Chem. Soc. Rev. 47, 172-194 (2018).

6. Ruan, J., Saidi, O., Iggo, J. A. \& Xiao, J. Direct acylation of aryl bromides with aldehydes by palladium catalysis. J. Am. Chem. Soc. 130, 10510-10511 (2008)

7. Jiang, X., Zhang, M.-M., Xiong, W., Lu, L.-Q. \& Xiao, W.-J. Deaminative (carbonylative) alkyl-Heck-type reactions enabled by photocatalytic C-N bond activation. Angew. Chem. Int. Ed. 58, 2402-2406 (2019).

8. Wang, J., Cary, B. P., Beyer, P. D., Gellman, S. H. \& Weix, D. J. Ketones from nickel-catalyzed decarboxylative, non-symmetric cross-electrophile coupling of carboxylic acid esters. Angew. Chem. Int. Ed. 58, 12081-12085 (2019). 
9. Bergonzini, G., Cassani, C. \& Wallentin, C.-J. Acyl radicals from aromatic carboxylic acids by means of visible-light photoredox catalysis. Angew. Chem. Int. Ed. 54, 14066-14069 (2015).

10. Dong, Z., Wang, J., Ren, Z. \& Dong, G. Ortho C-H acylation of aryl iodides by palladium/norbornene catalysis. Angew. Chem. Int. Ed. 54, 12664-12668 (2015).

11. Fu, M. C., Shang, R., Zhao, B., Wang, B. \& Fu, Y. Photocatalytic decarboxylative alkylations mediated by triphenylphosphine and sodium iodide. Science 363, 1429-1434 (2019).

12. Shi, R. \& Hu, X. From alkyl halides to ketones: nickel-catalyzed reductive carbonylation utilizing ethyl chloroformate as the carbonyl source. Angew. Chem. Int. Ed. 58, 7454-7458 (2019).

13. Nahm, S. \& Weinreb, S. M. $N$-methoxy- $N$-methylamides as effective acylating agents. Tetrahedron Lett. 22, 3815-3818 (1981)

14. Bechara, W. S., Pelletier, G. \& Charette, A. B. Chemoselective synthesis of ketones and ketimines by addition of organometallic reagents to secondary amides. Nat. Chem. 4, 228-234 (2012).

15. Steves, J. E. \& Stahl, S. S. Copper(I)/ABNO-catalyzed aerobic alcohol oxidation: alleviating steric and electronic constraints of $\mathrm{Cu} / \mathrm{TEMPO}$ catalyst systems. J. Am. Chem. Soc. 135, 15742-15745 (2013).

16. Wu, X. F., Neumann, H. \& Beller, M. Palladium-catalyzed carbonylative coupling reactions between Ar-X and carbon nucleophiles. Chem. Soc. Rev. 40, 4986-5009 (2011).

17. Guo, L. \& Rueping, M. Decarbonylative cross-couplings: nickel catalyzed functional group interconversion strategies for the construction of complex organic molecules. Acc. Chem. Res. 51, 1185-1195 (2018)

18. Wang, D. \& Zhang, Z. Palladium-catalyzed cross-coupling reactions of carboxylic anhydrides with organozinc reagents. Org. Lett. 5, 4645-4648 (2003).

19. Ben Halima, T. et al. Palladium-catalyzed Suzuki-Miyaura coupling of aryl esters. J. Am. Chem. Soc. 139, 1311-1318 (2017).

20. Hartwig, J. F. In Organotransition Metal Chemistry: from Bonding to Catalysis (University Science Books, Sausalito, 2010).

21. Biswas, S. \& Weix, D. J. Mechanism and selectivity in nickel-catalyzed crosselectrophile coupling of aryl halides with alkyl halides. J. Am. Chem. Soc. 135, 16192-16197 (2013).

22. Zhao, C., Jia, X., Wang, X. \& Gong, H. Ni-catalyzed reductive coupling of alkyl acids with unactivated tertiary alkyl and glycosyl halides. J. Am. Chem. Soc. 136, 17645-17651 (2014).

23. Yin, H., Zhao, C., You, H., Lin, K. \& Gong, H. Mild ketone formation via Nicatalyzed reductive coupling of unactivated alkyl halides with acid anhydrides. Chem. Commun 48, 7034-7036 (2012).

24. Ackerman, L. K., Lovell, M. M. \& Weix, D. J. Multimetallic catalysed crosscoupling of aryl bromides with aryl triflates. Nature 524, 454-457 (2015).

25. Wang, X., Wang, S., Xue, W. \& Gong, H. Nickel-catalyzed reductive coupling of aryl bromides with tertiary alkyl halides. J. Am. Chem. Soc. 137, 11562-11565 (2015).

26. Jin, Y. \& Wang, C. Nickel-catalyzed asymmetric reductive arylalkylation of unactivated alkenes. Angew. Chem. Int. Ed. 131, 6794-6798 (2019).

27. Ye, Y., Chen, H., Sessler, J. L. \& Gong, H. Zn-mediated fragmentation of tertiary alkyl oxalates enabling formation of alkylated and arylated quaternary carbon centers. J. Am. Chem. Soc. 141, 820-824 (2019).

28. Ni, S. et al. Ni-catalyzed deaminative cross-electrophile coupling of Katritzky salts with halides via $\mathrm{C}$ horizontal line $\mathrm{N}$ bond activation. Sci. Adv. 5, eaaw9516 (2019)

29. Poremba, K. E., Kadunce, N. T., Suzuki, N., Cherney, A. H. \& Reisman, S. E. Nickel-catalyzed asymmetric reductive cross-coupling to access 1,1diarylalkanes. J. Am. Chem. Soc. 139, 5684-5687 (2017).

30. He, R.-D. et al. Reductive coupling between $\mathrm{C}-\mathrm{N}$ and $\mathrm{C}-\mathrm{O}$ electrophiles. J. Am. Chem. Soc. 141, 12481-12486 (2019).

31. Zhang, M., Xie, J. \& Zhu, C. A general deoxygenation approach for synthesis of ketones from aromatic carboxylic acids and alkenes. Nat. Commun. 9, 3517 (2018).

32. Zhang, M., Yuan, X.-A., Zhu, C. \& Xie, J. Deoxygenative deuteration of carboxylic acids with $\mathrm{D}_{2} \mathrm{O}$. Angew. Chem. Int. Ed. 58, 312-316 (2019).

33. Ruzi, R. et al. Deoxygenative arylation of carboxylic acids by aryl migration. Chem. Eur. J. 25, 12724-12729 (2019).

34. Stache, E. E., Ertel, A. B., Tomislav, R. \& Doyle, A. G. Generation of phosphoranyl radicals via photoredox catalysis enables voltage-independent activation of strong C-O bonds. Acs. Catal. 8, 11134-11139 (2018).

35. Mao, R., Bera, S., Cheseaux, A. \& Hu, X. Deoxygenative trifluoromethylthiolation of carboxylic acids. Chem. Sci. 10, 9555-9559 (2019).

36. Welin, E. R., Le, C., Arias-Rotondo, D. M., McCusker, J. K. \& MacMillan, D. W. Photosensitized, energy transfer-mediated organometallic catalysis through electronically excited nickel(II). Science 355, 380-385 (2017).

37. Twilton, J. et al. The merger of transition metal and photocatalysis. Nat. Rev. Chem. 1, 0052 (2017).

38. Prier, C. K., Rankic, D. A. \& MacMillan, D. W. Visible light photoredox catalysis with transition metal complexes: applications in organic synthesis. Chem. Rev. 113, 5322-5363 (2013).
39. Milligan, J. A., Phelan, J. P., Badir, S. O. \& Molander, G. A. Alkyl carboncarbon bond formation by nickel/photoredox cross-coupling. Angew. Chem. Int. Ed. 58, 6152-6163 (2019).

40. Skubi, K. L., Blum, T. R. \& Yoon, T. P. Dual catalysis strategies in photochemical synthesis. Chem. Rev. 116, 10035-10074 (2016).

41. Wang, C. S., Dixneuf, P. H. \& Soule, J. F. Photoredox catalysis for building CC bonds from $\mathrm{C}\left(\mathrm{sp}^{2}\right)-\mathrm{H}$ bonds. Chem. Rev. 118, 7532-7585 (2018).

42. Schiavon, G., Zecchin, S., Cogoni, G. \& Bontempelli, G. Anodic oxidation of triphenylphosphine at a platinum electrode in acetonitrile medium. $J$. Electroanal. Chem. Interfac. 48, 425-431 (1973).

43. Zhang, X. \& MacMillan, D. W. C. Direct aldehyde C-H arylation and alkylation via the combination of nickel, hydrogen atom transfer, and photoredox catalysis. J. Am. Chem. Soc. 139, 11353-11356 (2017).

44. Schirmer, T. E., Wimmer, A., Weinzierl, F. W. C. \& König, B. Photo-nickel dual catalytic benzoylation of aryl bromides. Chem. Commun. 55, 10796-10799 (2019)

45. Chu, L., Lipshultz, J. M. \& MacMillan, D. W. Merging Photoredox and nickel catalysis: the direct synthesis of ketones by the decarboxylative arylation of alpha-oxo acids. Angew. Chem. Int. Ed. 54, 7929-7933 (2015).

46. Smith, R. T. et al. Metallaphotoredox-catalyzed cross-electrophile Csp(3)-Csp (3) coupling of aliphatic bromides. J. Am. Chem. Soc. 140, 17433-17438 (2018).

47. Konev, M. O., McTeague, T. A. \& Johannes, J. W. Nickel-catalyzed photoredox-mediated cross-coupling of aryl electrophiles and aryl azides. ACS Catal. 8, 9120-9124 (2018).

48. Ackerman, L. K. G., Martinez Alvarado, J. I. \& Doyle, A. G. Direct C-C bond formation from alkanes using Ni-photoredox catalysis. J. Am. Chem. Soc. 140, 14059-14063 (2018)

49. Zhu, C. et al. A multicomponent synthesis of stereodefined olefins via nickel catalysis and single electron/triplet energy transfer. Nat. Catal. 2, 678-687 (2019).

50. Yan, D.-M., Xiao, C. \& Chen, J.-R. Strong C( $\left.\mathrm{sp}^{3}\right)-\mathrm{H}$ arylation by synergistic decatungstate photo-HAT and nickel. Catal. Chem. 4, 2496-2498 (2018).

51. Meng, Q.-Y., Wang, S., Huff, G. S. \& König, B. Ligand-controlled regioselective hydrocarboxylation of styrenes with $\mathrm{CO}_{2}$ by combining visible light and nickel catalysis. J. Am. Chem. Soc. 140, 3198-3201 (2018).

52. Johnston, C. P., Smith, R. T., Allmendinger, S. \& MacMillan, D. W. Metallaphotoredox-catalysed $\mathrm{sp}(3)$-sp(3) cross-coupling of carboxylic acids with alkyl halides. Nature 536, 322-325 (2016).

53. Li, J., Luo, Y., Cheo, H. W., Lan, Y. \& Wu, J. Photoredox-catalysis-modulated, nickel-catalyzed divergent difunctionalization of ethylene. Chemistry $\mathbf{5}$, 192-203 (2019)

54. Le, C. C. \& MacMillan, D. W. Fragment couplings via $\mathrm{CO}_{2}$ extrusionrecombination: expansion of a classic bond-forming strategy via metallaphotoredox. J. Am. Chem. Soc. 137, 11938-11941 (2015).

55. Joe, C. L. \& Doyle, A. G. Direct acylation of Csp(3)-H bonds enabled by nickel and photoredox catalysis. Angew. Chem. Int. Ed. 55, 4040-4043 (2016).

56. Leeuwen, T., Buzzetti, L., Perego, L. A. \& Melchiorre, P. A redox-active nickel complex that acts as an electron mediator in photochemical Giese reactions. Angew. Chem. Int. Ed. 58, 4953-4957 (2019).

57. Zhang, L. \& Hashmi, A. S. K. The combination of benzaldehyde and nickelcatalyzed photoredox alkylation/arylation. Angew. Chem. Int. Ed. 58, 1823-1827 (2019).

58. Si, X., Zhang, L. \& Hashmi, A. S. K. Benzaldehyde- and nickel-catalyzed photoredox $\mathrm{C}\left(\mathrm{sp}^{3}\right)-\mathrm{H}$ alkylation/arylation with amides and thioethers. Org. Lett. 21, 6329-6332 (2019).

\section{Acknowledgements}

We thank the National Natural Science Foundation of China (21971108, 21971111, 21702098, 21732003, and 21672099), the Natural Science Foundation of Jiangsu Province (Grant No. BK20190006), Fundamental Research Funds for the Central Universities (020514380214), "Innovation \& Entrepreneurship Talents Plan" of Jiangsu Province, "1000-Youth Talents Plan", "Jiangsu Six Peak Talent Project", and start-up funds from Nanjing University for financial support. Y.L., K.L., C.Z., and W.X. are warmly acknowledged to reproduce experimental procedures for products $(3,23,24$ and 34).

\section{Author contributions}

J.X. conceived and supervised the whole project and wrote the paper with input from all authors. R.R., C.Z., and J.X. designed and discussed the experiments; R.R. and K.L. performed and analyzed the experiments.

\section{Competing interests}

J.X., R.R., and K.L. declare the following competing interests that one Chinese patent has been registered (201910828905.0). All other authors declare no competing interest. 


\section{Additional information}

Supplementary information is available for this paper at https://doi.org/10.1038/s41467020-17224-2.

Correspondence and requests for materials should be addressed to J.X.

Peer review information Nature Communications thanks the anonymous reviewer(s) for their contribution to the peer review of this work.

Reprints and permission information is available at http://www.nature.com/reprints

Publisher's note Springer Nature remains neutral with regard to jurisdictional claims in published maps and institutional affiliations. (c) (i) Open Access This article is licensed under a Creative Commons Attribution 4.0 International License, which permits use, sharing, adaptation, distribution and reproduction in any medium or format, as long as you give appropriate credit to the original author(s) and the source, provide a link to the Creative Commons license, and indicate if changes were made. The images or other third party material in this article are included in the article's Creative Commons license, unless indicated otherwise in a credit line to the material. If material is not included in the article's Creative Commons license and your intended use is not permitted by statutory regulation or exceeds the permitted use, you will need to obtain permission directly from the copyright holder. To view a copy of this license, visit http://creativecommons.org/licenses/by/4.0/.

(C) The Author(s) 2020 